\title{
ACESSO À JUSTIÇA E MAIORES LITIGANTES NO BRASIL: OS MÉTODOS NÃO CONVENCIONAIS DE SOLUÇÃO DE CONTROVÉRSIAS COMO INSTRUMENTO DE REDUÇÃO DESSA LITIGIOSIDADE ESPECÍFICA
}

\author{
ACCESS TO JUSTICE AND BIGGEST LITIGANTES IN BRAZIL: ADRS ( ALTERNATIVE \\ DISPUTE RESOLUTION) SETTLEMENT AS AN INSTRUMENT OF REDUCTION OF THAT \\ PARTICULAR LITIGATION
}

\author{
${ }^{1}$ Mônica Bonetti Couto \\ ${ }^{2}$ Simone Pereira de Oliveira
}

\section{RESUMO}

Este artigo tem por finalidade analisar a participação dos maiores litigantes do país como um dos fatores de congestionamento do Poder Judiciário, capaz de prejudicar a efetivação do acesso à justiça, bem como a boa qualidade de seus serviços. Parte-se da hipótese de que os meios não convencionais de solução de controvérsia poderão ser empregados como instrumentos auxiliares de redução da morosidade judicial, possibilitando a resolução dos litígios sem a provocação da máquina estatal. Para tanto, servir-se-á do método dedutivo, sob a forma de pesquisa bibliográfica.

Palavras-chave: Acesso à justiça, Grandes litigantes, Métodos não convencionais de solução de controvérsias

\begin{abstract}
This article aims to analyze the participation of the largest litigators in the country as one of the congestion factors of the judiciary and how circumstances can undermine the effectiveness of access to justice broadly and the good quality of judicial services. Start from the assumption that the alternative means of dispute settlement, conciliation, mediation and arbitration may be used as auxiliary tools to reduce delays, allowing the resolution of disputes without the provocation of the state machine. To this end, we use the deductive method in the form of literature.
\end{abstract}

Keywords/: Access to justice, Large litigants, Alternative dispute resolution

\footnotetext{
${ }^{1}$ Doutora em Direito pela Pontifícia Universidade Católica - PUC, São Paulo, (Brasil). Professora e Pesquisadora do Programa de Mestrado em Direito da Universidade Nove de Julho - UNINOVE, São Paulo. E-mail: monicabonetticouto@ yahoo.com.br

${ }^{2}$ Mestranda do Programa de Mestrado em Direito da Universidade Nove de Julho - UNINOVE, São Paulo. E-mail:

simonepereira2309@gmail.com
} 


\section{INTRODUÇÃO}

O presente artigo tem por finalidade analisar a participação dos maiores litigantes do país como um dos fatores de congestionamento do Poder Judiciário e como circunstância capaz de prejudicar a efetivação do acesso à justiça de forma ampla, enquanto acesso a uma ordem jurídica justa, e a boa qualidade dos serviços judiciários.

Procurar-se-á enfrentar as questões atinentes à possibilidade de redução do impacto da atuação dos grandes litigantes no congestionamento do Poder Judiciário, por intermédio dos meios não convencionais de solução de controvérsias.

Adotando-se a modalidade de pesquisa bibliográfica, parte-se da hipótese de que a atuação dos grandes litigantes, assim considerados pelo relatório "100 MAIORES LITIGANTES", do CNJ, representa conduta desprovida de compromisso com a coletividade, com a melhora da prestação jurisdicional e com o perfazimento do acesso à justiça enquanto ordem jurídica justa e à população como um todo, utilizando-se como referência, especialmente neste aspecto, a pesquisa "O uso da justiça e o litígio no Brasil”, publicada pela Associação Brasileira de Magistrados, em menção ao estudo dos 100 maiores litigantes.

O trabalho está estruturado em três subseções ou itens, ao que se seguem as considerações finais.

No primeiro item, com esteio nas obras de Cappelletti e Garth e de Rodolfo de Camargo Mancuso, utilizados como referenciais teóricos, discorrer-se-á sobre o acesso à justiça, concebendo-o como instrumento de garantia dos direitos do cidadão superando a mera perspectiva do direito de ajuizar uma demanda.

No item 2, serão trazidos parte dos dados divulgados pelo Departamento de Pesquisas Judiciárias do CNJ por meio do relatório denominado "100 MAIORES LITIGANTES”, divulgado em 2011, ocasião em que se examinará, mais especificamente, os dados referentes aos 100 maiores litigantes da Justiça Estadual e o impacto da conduta de tais atores na (dificuldade de) efetivação do acesso à justiça e na (in)evolução da qualidade dos serviços judiciários. 
Por fim, abordar-se-ão, em linhas gerais, os métodos não convencionais de solução de controvérsias enquanto mecanismos auxiliares para a redução da altíssima taxa de litigiosidade decorrente da atuação dos grandes litigantes mencionados no trabalho. Nessa oportunidade, procurar-se-á investigar a possibilidade de aplicação de tais técnicas - a saber, da conciliação, da mediação e da arbitragem - como instrumentos efetivos de resolução dos litígios e, por isso, de sensível redução do assustador quadro de procura pela tutela jurisdicional.

\section{O ACESSO À JUSTIÇA ENQUANTO DIREITO A UMA ORDEM JURÍDICA JUSTA OU UMA VISÃO ALÉM DO JUDICIÁRIO}

Como é cediço, a Constituição da República de 1988 traz o acesso à justiça erigido à garantia fundamental, estabelecendo, no inciso XXXV, de seu art. $5^{\circ}$ que " a lei não excluirá da apreciação do Poder Judiciário lesão ou ameaça a direito."

Tal direito, a bem da verdade, como muito bem se registra na doutrina, pode ser encarado como o requisito fundamental - ou, como preferem, o [ou um dos] "mais básico dos direitos humanos" - "de um sistema jurídico moderno e igualitário que pretenda garantir, e não apenas proclamar os direitos de todos" (CAPPELLETTI e GARTH (1998, p. 4-5).

Ocorro que há muito se rechaça a ideia de compreender o acesso à justiça como simples acesso ao Poder Judiciário ou, em outras palavras, ao direito fundamental de obtenção da tutela jurisdicional. Necessário compreendê-lo como o direito a uma ordem jurídica justa.

Precisamente a esse respeito, vale transcrever as oportunas lições de LEITE (CEZAR, 2014)

\footnotetext{
"O termo acesso à justiça pode ser entendido em sentido amplo e em sentido estrito. Este concerne a ideia formal do acesso efetivo à prestação jurisdicional para solução de conflitos intersubjetivos. Aquele possui significado mais abrangente, na medida em que abraça também o primeiro sentido, e vai além. Noutro fala, a moderna concepção de acesso à justiça não é apenas formal, mas substancial. Significa, portanto o acesso a uma ordem política, jurídica, econômica e socialmente justa.”
} 
Em verdade, quando se fala de acesso à justiça objetiva-se garantir os direitos do cidadão e não apenas o seu direito de ajuizar uma demanda. Por isso, é preciso pensar o acesso à justiça com visão que vai além do Judiciário.

Realmente, a possibilidade de empregar os meios alternativos de solução de controvérsia como via extrajudicial de solução de litígios com o objetivo de satisfazer a pretensão das partes com maior agilidade e, ao mesmo tempo, aliviar a demanda jurisdicional, isso porque, como ensina KAZUO WATANABE, o inc. XXXV do art. $5^{\circ}$ da Constituição Federal deve ser interpretado

\begin{abstract}
não apenas como garantia de mero acesso aos órgãos do Poder Judiciário, mas como garantia de acesso à ordem jurídica justa, de forma efetiva, tempestiva e adequada. Daí a conclusão de que cabe ao Poder Judiciário, pelo $\mathrm{CNJ}$, organizar os serviços de tratamento de conflitos por todos os meios adequados, e não apenas por meio da adjudicação de solução estatal em processos contenciosos, cabendo-lhe em especial institucionalizar, em caráter permanente, os meios consensuais de solução de conflitos de interesses, como a mediação e a conciliação. ${ }^{1}$
\end{abstract}

Assim, conforme CAPPELLETTI e GARTH (1998, p. 12-25; p. 30/32) reconhece-se a incapacidade de o Estado resolver todos os litígios e necessidade do emprego de meios alternativos de resolução de disputas - ADRs (acesso a uma solução efetiva parar o conflito por meio da participação adequada do Estado), salientando-se que a utilização de métodos alternativos endossa os esforços envidados para incrementar o acesso à justiça.

No Brasil, o acesso à justiça tem sido atingido pelos efeitos da morosidade da entrega da prestação jurisdicional, que espelha a crise do judiciário que pode ser atribuída, em breves linhas, a uma somatória de fatores como o crescimento da busca pela tutela jurisdicional evidenciada pela elevada e progressiva distribuição dos feitos, o insuficiente número de magistrados e a deficitária infraestrutura estatal.

Como preconiza COUTO (2013, p. 132-133)

A chamada "Crise da Justiça" é assunto em torno do qual tem gravitado discussões dos mais diversos grupos, de juristas a leigos, passando pela opinião pública e notadamente pela grande mídia, que lhe tem dado singular destaque. Aliás, não é de hoje que temos percebido - e afirmado - encontrarse "na ordem do dia a discussão em torno do grave problema da excessiva lentidão do Judiciário, comumente atribuída ao assustador volume de

\footnotetext{
${ }^{1}$ Política Pública do Poder Judiciário Nacional para tratamento adequado dos conflitos de interesses. Parecer ao TJ-SP. $\quad$ Disponível em http://www.tjsp.jus.br/download/conciliacao/nucleo/parecerdeskazuowatanabe.pdf, acesso em 25.01.2016
} 
processos que tramitam nos Juízos e Tribunais brasileiros, sobrecarregandoos demasiadamente".

Em tal cenário, afigura-se oportuna a discussão relativa à participação dos grandes litigantes no processo de congestionamento do Poder Judiciário e o potencial lesivo de sua conduta em prejudicar o acesso à justiça dos demais cidadãos e comprometer a qualidade do serviço judiciário prestado.

Importa, pois, pensar o acesso à justiça além da perspectiva do acesso ao judiciário, como forma de garantia de direitos por meio de instrumentos variados como os meios alternativos de solução de controvérsias, sendo oportuno e bem-vindo o ideal de Justiça Compartilhada "com outros agentes, órgãos e instâncias capazes de prevenir ou resolver conflitos com a justiça, em tempo razoável e sob uma boa equação custo benefício" (MANCUSO, 2011, p. 473).

Realmente, a noção do compartilhamento com outros meios de solução de controvérsia pode representar diminuição nas taxas de litigiosidade ${ }^{2}$ específica, como será abordado no item 3, infra.

\section{OS GRANDES LITIGANTES DO PAÍS E SUA PARTICIPAÇÃO NO AUMENTO DE PROCESSOS JUDICIAIS}

O Departamento de Pesquisas Judiciárias do Conselho Nacional de Justiça, em março de 2011, divulgou um relatório denominado "100 MAIORES LITIGANTES", resultante do recebimento de dados coletados e enviados pelos tribunais estaduais, regionais federais e do trabalho, sobre os seus maiores litigantes, dos referentes a processos sem baixa definitiva até o dia 31 de março de 2010.

O relatório em comento divulgou dados referentes à Listagem dos 100 maiores litigantes; dos 100 maiores litigantes por Setor e Justiça; dos 100 maiores litigantes Nacionais; dos 100 maiores litigantes da justiça federal; dos 100 maiores litigantes da justiça do trabalho e dos 100 maiores litigantes da justiça estadual.

\footnotetext{
${ }^{2}$ Cf. COUTO, Mônica Bonetti; TEIXEIRA, Laís Santana da Rocha Salvetti. O (direito fundamental ao) acesso à justiça no Brasil: por uma correta compreensão. In: CASTRO, Matheus de; PEZZELA, Maria Cristina Cereser; RECKZIEGEL, Janaína. (org.). Direitos fundamentais civis: a ampliação dos direitos subjetivos no Brasil e na Alemanha (tomo II). 1 ed. Joaçaba: Unoesc, 2013, pp. 155-171.
} 
Nesse trabalho consideraremos os dados referentes aos 100 maiores litigantes nacionais por setor e aos 100 maiores litigantes estaduais por setor, com base nos resultados expressos nos gráficos $1,2,7$, e 8 , que adiante estão expostos:

Gráfico 1 - Percentual de processos dos 100 maiores litigantes nacionais por setor:

\begin{tabular}{|l|r|}
\hline SETOR PÚBLICO FEDERAL & $38 \%$ \\
\hline BANCOS & $38 \%$ \\
\hline SETOR PÚBLICO ESTADUAL & $8 \%$ \\
\hline TELEFONIA & $6 \%$ \\
\hline SETOR PÚBLICO MUNICIPAL & $5 \%$ \\
\hline OUTROS & $5 \%$ \\
\hline
\end{tabular}

Gráfico 2 - Quantitativo do total de processos dos 100 maiores litigantes nacionais com percentual entre os polos ativo e passivo: ${ }^{3}$

\begin{tabular}{|l|c|c|}
\cline { 2 - 3 } \multicolumn{1}{c|}{} & Pólo ativo & Pólo passivo \\
\hline SETOR PÚBLICO FEDERAL & $33 \%$ & $67 \%$ \\
\hline BANCOS & $45 \%$ & $55 \%$ \\
\hline SETOR PÚBLICO ESTADUAL & $28 \%$ & $72 \%$ \\
\hline TELEFONIA & & $78 \%$ \\
\hline SETOR PÚBLICO MUNICIPAL & $97 \%$ & \\
\hline OUTROS & $49 \%$ & \\
\hline
\end{tabular}

Gráfico 7 - Percentual de processos dos 100 maiores litigantes da Justiça Estadual por setor.

\begin{tabular}{|l|c|}
\hline BANCOS & $53,5 \%$ \\
\hline SETOR PÚBLICO ESTADUAL & $14,0 \%$ \\
\hline SETOR PÚBLICO MUNICIPAL & $10,0 \%$ \\
\hline TELEFONIA & $9,6 \%$ \\
\hline SETOR PÚBLICO FEDERAL & $7,0 \%$ \\
\hline OUTROS & $5,8 \%$ \\
\hline
\end{tabular}

\footnotetext{
${ }^{3}$ Os percentuais referentes aos polo ativo da Telefonia, e dos polos passivos do setor público municipal e outros foram deixados em branco por falta de tais dados no Relatório do CNJ, conforme se verifica na págia 15.
} 
Gráfico 8 - Quantitativo do total de processos dos 100 maiores litigantes Justiça Estadual com percentual entre os polos ativo e passivo. ${ }^{4}$

\begin{tabular}{|l|l|c|}
\hline & Polo ativo & Polo passivo \\
\hline BANCOS & $52 \%$ & $48 \%$ \\
\hline SETOR PÚBLICO ESTADUAL & $29 \%$ & $71 \%$ \\
\hline SETOR PÚBLICO MUNICIPAL & $98 \%$ & \\
\hline TELEFONIA & & $77 \%$ \\
\hline SETOR PÚBLICO FEDERAL & & $79 \%$ \\
\hline OUTROS & & $55 \%$ \\
\hline
\end{tabular}

Uma reflexão sobre os dados permite-nos constatar que do percentual de processos dos 100 maiores litigantes nacionais por setor (gráfico 1), 95\% representam processos em que figuram como partes o setor público (Federal, Estadual e Municipal), bancos e empresas de telefonia.

Como bem esclarece o Departamento de Pesquisas Judiciárias,

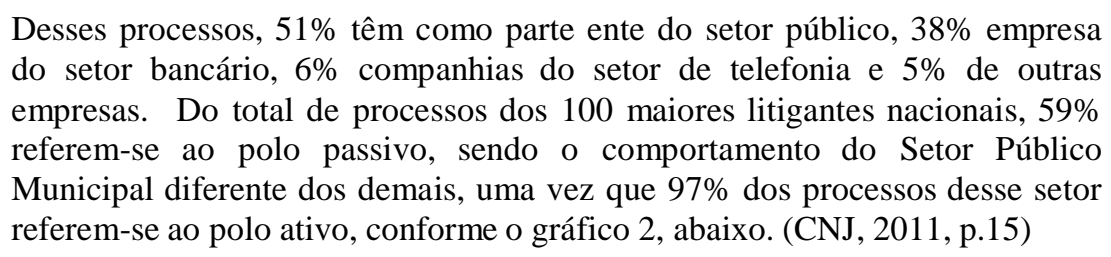

Análise idêntica permite-nos constatar que do percentual dos 100 maiores litigantes da Justiça Estadual, 94\% representam o setor público (Estadual, Municipal e Federal), bancos e telefonia, dos quais cerca de $54 \%$ dos processos têm como parte empresas do setor bancário, $31 \%$ entes do setor público, $10 \%$ empresas do setor de telefonia e $6 \%$ outras empresas (o gráfico 7).

Mais uma vez, bem observou o Departamento de Pesquisas Judiciárias que

Diferentemente das demais Justiças, o percentual de processos em litígio no polo passivo (52\%) dos 100 maiores litigantes da Justiça Estadual não foi muito diferente do polo ativo (48\%). O comportamento do Setor Público Municipal foi bastante diferente dos demais, uma vez que $98 \%$ dos processos

\footnotetext{
${ }^{4}$ Os percentuais referentes aos polos passivo do Setor Público Municipal e dos polos ativos da Telefonia, do setor público Federal e outros foram deixados em branco por falta de tais dados no Relatório do CNJ, conforme se verifica na página 23.
} 
desse setor foram referentes ao polo ativo, conforme gráfico 8, abaixo. (CNJ, 2011 , p. 23)

Ocupando-nos especificamente dos dados referentes aos 100 maiores litigantes da Justiça Estadual, inicialmente, consideraremos a influência do setor privado composto pelos setores bancário e da telefonia que movimentam cerca de $54 \%$ e $10 \%$ dos processos, respectivamente, totalizando a soma de quase $64 \%$ da demanda jurisdicional considerada.

Em se tratando de pessoas jurídicas de direito privado com fins lucrativos, conquanto dos processos considerados os bancos figurem como sujeito passivo em $48 \%$ deles e as empresas de telefonia se encontrem em igual situação em $77 \%$ das demandas estaduais em que participam, não parece razoável supor que a provocação que tal situação lhes seja economicamente desfavorável.

É que tanto os bancos como as empresas de telefonia poderiam manter departamentos voltados à resolução amigável das queixas dos clientes, no caso de relação de consumo, evitando o ajuizamento de ações judiciais.

Não há dúvidas de que numa economia capitalista as empresas busquem aumentar seus lucros mediante práticas que considerem oferecer maior eficiência econômica. Analisando o Direito sob o prisma econômico, LEAL (2010, p. 54), afirma que a eficiência econômica

\begin{abstract}
tem como pressuposto fundante a ideia do individualismo metodológico e das escolhas racionais, no sentido de que os indivíduos agem sempre de forma a maximizar sua satisfação respondendo racionalmente a incentivos e desincentivos externos.
\end{abstract}

Em tal cenário, as escolhas individuais prevaleceriam sobre o interesse coletivo, na forma em que, tratando sobre o mesmo assunto, pontua COELHO (2007, p. 10, apud LEAL, 2010, p. 54)

$\mathrm{Na}$ perspectiva desse individualismo metodológico, todas a as análises referentes a arranjos sociais devem, em último grau, estarem edificadas sobre a apreciação da conduta dos indivíduos, resultando daqui que os fenômenos coletivos devem ser explicados apenas como o resultado agregado de escolhas individuais. Para esta análise Econômica do Direito, portanto, os efeitos de determinada norma sobre o bem-estar coletivo podem e devem ser apreciados sob a perspectiva da soma das respostas individuais a tais normas. Ademais, a própria escolha das normas aplicáveis a cada caso reflete decisões individuais, e não planos coletivos, uma vontade geral do povo ou leis da história. 
Assim, nessa perspectiva, depreende-se que relativamente às escolhas racionais, LEAL (2010, p. 54), os indivíduos tomam suas decisões sopesando a maximização dos benefícios em detrimento dos custos decorrentes de suas condutas, sem levar em consideração os impactos que suas opções possam causar à coletividade.

Com base nas premissas da eficiência econômica (individualismo metodológico e escolhas racionais), LEAL (2010, p. 55) exterioriza interessante reflexão sobre a utilização do Poder Judiciário com o intento de obtenção de proveito econômico por um determinado conjunto de empresas, como se pode conferir

\begin{abstract}
Em termos jurídicos, pode-se associar a estas premissas a nefasta experiência de um pequeno conjunto de 16 (dezesseis) empresas que se encontram como requeridas em processos judiciais absolutamente recorrentes envolvendo os segmentos bancários (alienações fiduciárias, leasing, arrendamento mercantil), telefonia, administração de cartões de crédito e serviços públicos, representando cerca de $45 \%$ do total de feitos ajuizados nos juizados especiais do Rio de Janeiro, entre 2002 e 2004..$^{5} \mathrm{Na}$ base destes comportamentos temerários, encontra-se o cálculo/escolha racional destas empresas que apostam em estratégias protelatórias para cumprir com suas obrigações, eis que concluíram serem os custos impostos pelo sistema de justiça mais vantajosos do que alterarem toda uma política de tratamento do consumidor, pois dos milhões de clientes que possuem apenas pequena parcela recorre ao Poder Judiciário para reclamar seus direitos; quando reclamam, o tempo do processo e da resposta final é igualmente benéfica para seus interesses de lucro.
\end{abstract}

Há outro aspecto, todavia, relacionado com a cultura do conflito que graça na sociedade brasileira, como se todos os problemas intersubjetivos devessem ser tutelados pelo Estado (Juiz). Isto leva ao que posso chamar de paradoxo da eficiência, ora entendido como o fenômeno em que, mesmo aumentando as possibilidades de acesso à justiça para a sociedade civil, isto opera como fomento à judicialização das relações sociais, implodindo o sistema de justiça com números incontroláveis de processos a serem julgados - ex vi o exemplo dos juizados especiais hoje. (LEAL, 2010, p. 77)

Em verdade, quanto aos bancos e as empresas de telefonia, parece-nos adequada a tese de LEAL no sentido de que para tal segmento é mais vantajoso sujeitarse a uma ação judicial do que manter ou instituir um sistema administrativo de tratamento adequado ao consumidor, pois, apenas uma parcela dos clientes insatisfeitos optará por provocar a tutela jurisdicional ou terá condições de fazê-lo.

Pertinente, ainda, a consideração de LEAL quanto a persistência da cultura do conflito na sociedade brasileira e a possibilidade de que a manutenção de tal

\footnotetext{
${ }^{5}$ Dados correspondentes à nota de rodapé ${ }^{\circ} 83$ do autor que refere: “conforme pesquisa intitulada Perfil das maiores demandas judiciais do TJERJ.”,p. 55
} 
mentalidade continue provocando o congestionamento processual do Poder Judiciário caso o objetivo de solução dos processos em tempo adequado seja atingido. É que uma justiça mais célere poderia incentivar o aumento da distribuição de processos judiciais.

Embora evidenciada a representativa parcela de responsabilidade da postura dos representantes dos setores bancário e de telefonia para o aumento de demandas judiciais, muitas vezes o próprio consumidor coopera para a litigação excessiva ${ }^{6}$, pois sequer tenta resolver sua queixa com a própria instituição prestadora do serviço.

Tal constatação encontra amparo no relatório Demandas Repetitivas e a Morosidade Judicial, divulgado em julho de 2011 e resultante de uma parceria entre o Conselho Nacional de Justiça, a Fundação Getúlio Vargas (FGV-SP), a Pontifícia Universidade Católica do Paraná (PUC-PR) e a Pontifícia Universidade Católica do Rio Grande do Sul (PUC-RS), com se pode verificar

\begin{abstract}
No estudo de caso sobre direito do consumidor, com foco sobre contratos bancários, observa-se a existência de canais independentes de resolução de conflitos que permitem ao consumidor optar em qual esfera (extrajudicial ou judicial) tentará resolver o seu problema. Em muitos casos, os consumidores procuram o Judiciário antes mesmo de tentar uma resolução nas esferas extrajudiciais.

Verifica-se que existem muitos incentivos para o aumento da judicialização dos conflitos na área de direito do consumidor: o baixo custo de ingressar com ações aliado a uma grande possibilidade de sucesso, especialmente nos Juizados Especiais; (CNJ, 2011, p. 7)
\end{abstract}

Nesse cenário, os meios alternativos de solução de controvérsias, a conciliação, a mediação e a arbitragem emergem como instrumentos adequados a conciliar, resolver os conflitos conferindo maior autonomia às partes e sem a provocação do Poder Judiciário, favorecendo a diminuição da taxa de congestionamento processual, inclusive nas hipóteses em que o Poder Público integre a relação jurídica processual.

\footnotetext{
${ }^{6}$ No concernente à litigação excessiva, o Departamento de Pesquisas Judiciárias do Conselho Nacional de Justiça elaborou, em 2011 (p.9), o relatório denominado "ESTUDO COMPARADO SOBRE RECURSOS, LITIGIOSIDADE E PRODUTIVIDADE: a prestação jurisdicional no contexto internacional”, no qual é feita a seguinte observação quanto à a influência da cultura do litígio nos advogados e sua pouca propensão à realização de conciliações: "De acordo com estudo recentemente contratado pelo CNJ sob responsabilidade da PUC-RS, a acirrada concorrência no mercado de serviços advocatícios e a pouca propensão desses profissionais à realização de conciliações são fatores apontados como responsáveis pelo estímulo à litigância no Brasil."
} 


\section{OS MEIOS NÃO CONVENCIONAIS DE SOLUÇÃO DE CONTROVÉRSIAS ENQUANTO MECANISMOS AUXILIARES À REDUÇÃO DESSA TAXA DE LITIGIOSIDADE ESPECÍFICA}

Amplamente amparado nas lições de William Ury, Pedro A. Batista Martins afirma que "Não é a maior ou a menor litigiosidade que determina o maior grau de civilização de uma sociedade e, sim, os meios pelos quais os conflitos são resolvidos". Martins afirma que "Nas sociedades enfermas a maioria das controvérsias resolvem-se com base no poder, muitas em razão do direito e poucas conforme os interesses" e que nas sociedades saudáveis a maior parte das disputas solucionam-se conciliando interesses (negociação, mediação), algumas por meio da jurisdição e raríssimas pelo poder. $(1999$, p. 7$)$

Segundo Martins, é preciso privilegiar a instrumentalidade do processo, repudiar o protecionismo Estatal expresso num intransigente monopólio da jurisdição e incentivar a utilização dos meios alternativos de resolução de conflitos (1999, p. 12-13)

Dentre os meios não convencionais de solução de controvérsias cumpre-nos discorrer sobre a negociação, a conciliação, a mediação e a arbitragem.

A negociação pode ser compreendida como método alternativo - ou, como preferimos, não convencionais - de solução de litígios que mais se identifica com relações negociais em que é visado o ganho recíproco e que, segundo ALVARES (2012, p. 77), pode ser definida como

\footnotetext{
a resolução direta de divergências pelas partes. Normalmente, é utilizada para contratação em geral - formação da relação jurídica. Podemos visualizar uma preponderância de utilização da negociação entre pessoas jurídicas que negociam trocas de vantagens e diminuição de perdas.
}

A conciliação é a modalidade autocompositiva de solução de controvérsia na qual o terceiro facilitador pode adotar uma posição mais ativa, porém neutra com relação ao conflito e imparcial. É um processo consensual breve, que busca uma efetiva harmonização social e a restauração, dentro dos limites possíveis, da relação social das partes. 
A mediação ${ }^{7}$, a seu turno, consiste na forma autocompositiva de resolução controvérsias em que um terceiro imparcial auxilia as partes a chegarem por si mesmas a um denominador comum, estabelecendo um acordo, por meio de um processo estruturado "que representa uma fusão das teorias e das práticas das disciplinas da psicologia, assessoria, direito e outros serviços do campo das relações humanas. " (GARCEZ, 2004, p.39-40)

Os dois institutos orientam-se por princípios como informalidade, simplicidade, economia processual, celeridade, oralidade e flexibilidade processual. ${ }^{8}$

A Resolução n” 125/2010 do CNJ, que "Dispõe sobre a Política Judiciária Nacional de tratamento adequado dos conflitos de interesses no âmbito do Poder Judiciário e dá outras providências", instituiu, em seu anexo III, o Código de Ética de Conciliadores e Mediadores Judiciais estabelecendo como princípios fundamentais para sua atuação a confidencialidade, a competência, a imparcialidade, a neutralidade, a independência e autonomia e o respeito à ordem pública e às leis vigentes (art. $1^{\circ}$ ).

O Novo Código de Processo Civil, Lei n 13.105, de 16 de março de 2015, em seu Livro I, Título Único, Capítulo I - Das Normas Fundamentais do Processo Civil, emprestou especial tratamento à arbitragem e aos métodos autocompositivos de solução de controvérsias, conforme se verifica do que constou, expressamente, dos parágrafos de seu art. $3^{\circ}$, adiante transcrito:
Art. 3ํ№̃o se excluirá da apreciação jurisdicional ameaça ou lesão a direito.
$\S 1^{\mathrm{o}}$ É permitida a arbitragem, na forma da lei.
$\S 2^{\circ} \mathrm{O}$ Estado promoverá, sempre que possível, a solução consensual dos conflitos.
$\S 3^{\circ}$ A conciliação, a mediação e outros métodos de solução consensual de conflitos deverão ser estimulados por juízes, advogados, defensores públicos e membros do Ministério Público, inclusive no curso do processo judicial.

Sobreveio a Lei no 13.140, de 26 de junho de 2015, que "Dispõe sobre a mediação entre particulares como meio de solução de controvérsias e sobre a autocomposição de conflitos no âmbito da administração pública", vindo a prever, expressamente, a mediação como meio de solução de controvérsias entre particulares e

\footnotetext{
${ }^{7}$ No termos do parágrafo único, do art. $1^{\text {o }}$, da Lei n 13.140/2015, "Considera-se mediação a atividade técnica exercida por terceiro imparcial sem poder decisório, que, escolhido ou aceito pelas partes, as auxilia e estimula a identificar ou desenvolver soluções consensuais para a controvérsia".

${ }^{8}$ CNJ Programas e ações. Mediação e conciliação. Disponível em http://www.cnj.jus.br/programas-eacoes/conciliacao-mediacao, acesso em 25.01.2016
} 
fazendo constar também a autocomposição de conflitos no âmbito da Administração Pública $\left(\operatorname{art} .1^{\circ}\right)$.

Referida lei prevê a mediação judicial e a extrajudicial, cada uma com regulamentação específica (arts. 14 a 29), e cuida da autocomposição de conflitos em que for parte pessoa jurídica de direito público, em seu capítulo II, seção I.

$\mathrm{O}$ art. 32 da Lei 13.140/2015 faculta às pessoas jurídicas de direito público a criação de câmaras de prevenção e resolução administrativa de conflitos, no âmbito de seus respectivos órgãos da Advocacia Pública, onde houver, com competência para dirimir conflitos entre órgãos e entidades da Administração Pública, avaliar a admissibilidade de pedidos de resolução conflitos formulados por particulares contra a Administração, por meio de composição, e promover, no que couber termo de ajustamento de conduta.

Há previsão expressa de aplicação da autocomposição em matéria tributária (art. 34, $\S 2^{\circ}$ ) e os critérios de transação por adesão dos conflitos envolvendo a Administração Pública Federal Direta, suas Autarquias e Fundações, estão disciplinados na Seção II, da Lei no 13.140/2015 (arts. 35 a 40) e mediação nas relações de trabalho foi destinada a regulamentação própria (art. 42, parágrafo único).

Exatamente um mês antes, no dia 26 de maio de 2015, foi editada a Lei $\mathrm{n}^{\circ}$ 13.129 ${ }^{9}$, que alterou a Lei 9.307/96, que dispõe sobre a arbitragem, estendendo a possibilidade de utilização da arbitragem para dirimir litígios relativos a direitos patrimoniais disponíveis, faculdade até então restrita aos particulares (pessoas capazes), às pessoas jurídicas de direito público $\left(\operatorname{art.} 1, \S 1^{\circ}\right)$.

A arbitragem entre particulares pode ser de direito ou de equidade, restringindo-se a arbitragem que envolva a Administração Pública à modalidade de direito, respeitado o princípio da publicidade $\left(\operatorname{art.} 2^{\circ}, \S \S 1^{\circ}\right.$ e $\left.2^{\circ}\right)$.

Quanto às relações de consumo, comungamos do entendimento de Carlos Alberto Carmona, no sentido de que a relação jurídica que envolve consumidor e fornecedor de bens e serviços é disponível (2006, p. 68), sendo evidente que ao art. 57 , inciso VII, da Lei $\mathrm{n}^{\circ} 8.078 / 90$, apenas considerou nulas de pleno direito as abusivas a

\footnotetext{
${ }^{9}$ Referida lei alterou também a Lei no $6.404 / 76$, lei das sociedades anônimas.
} 
inserção compulsória de cláusula compulsória de arbitragem nos contratos, de sorte que, havendo comum acordo, o instituto da arbitragem pode e deve ser aplicado nas relações de consumo.

Relativamente à redução da taxa de litigiosidade específica referente ao número de processos em que figuram como partes o Poder Público, os bancos e as empresas de telefonia, constatamos das análises realizadas que os meios alternativos de solução de controvérsias podem e devem ser utilizados como mecanismos auxiliares ao descongestionamento do Poder Judiciário proporcionando a solução dos conflitos na esfera extrajudicial ou mesmo, abreviando-se a solução da demanda por intermédio da conciliação ou da mediação judicial.

Quanto à atuação dos grandes litigantes, o acesso à justiça e à qualidade dos serviços judiciários, consta da pesquisa intitulada $\mathrm{O}$ uso da justiça e o litígio no Brasil, publicada em agosto/2015, pela Associação Brasileira de Magistrados, em menção ao estudo dos 100 maiores litigantes em 11 unidades da federação, que "Maria Tereza Sadek destaca que a elevada concentração de processos nas mãos de poucos litigantes resulta em prejuízos ao acesso à Justiça e na qualidade dos serviços judiciários prestados à sociedade em geral.” (2015, p. 12)

Alinhamo-nos, nesse passo, ao pensamento de Maria Tereza Sadek e reputamos verificada a hipótese de que a atuação os dos grandes litigantes prejudica o acesso à justiça e a qualidade dos serviços judiciários, pois a máquina estatal acaba por dispensar boa parte seu tempo e recursos humanos na tramitação de processos que veiculam questões passíveis de composição ou solução extrajudicial.

\section{CONCLUSÃO}

Relativamente à abordagem do acesso à justiça enquanto direito a uma ordem jurídica justa, constatamos tratar-se de garantia constitucional e de um instrumento que possibilita assegurar os demais direitos.

Sob esse prisma, consideramos que, em nosso país, o acesso à justiça tem sido atingido pelos efeitos da morosidade da entrega da prestação jurisdicional, que espelha a 
crise do judiciário que pode ser atribuída a uma somatória de fatores como o crescimento da busca pela tutela jurisdicional e, neste aspecto, oportuna a discussão relativa à participação dos grandes litigantes no processo de congestionamento do Poder Judiciário e o potencial lesivo de sua conduta em prejudicar o acesso à justiça dos demais cidadãos e comprometer a qualidade do serviço judiciário prestado.

Em decorrência disso, analisamos parcialmente o relatório denominado "100 MAIORES LITIGANTES”, divulgado pelo Departamento de Pesquisas Judiciárias do Conselho Nacional de Justiça. Consideramos os dados referentes aos 100 maiores litigantes nacionais por setor e aos 100 maiores litigantes estaduais por setor, com base nos gráficos 1, 2, 7, e 8, anteriormente expostos, ocupando-nos especificamente dos dados referentes aos 100 maiores litigantes da Justiça Estadual, inicialmente, considerando a influência do setor privado composto pelos setores bancário e da telefonia que movimentam cerca de $54 \%$ e $10 \%$ dos processos, respectivamente, totalizando a soma de quase $64 \%$ da demanda jurisdicional considerada.

Verificamos que tanto os bancos como as empresas de telefonia, embora tenham a possibilidade de manter departamentos voltados à resolução amigável das queixas dos clientes, no caso de relação de consumo, evitando o ajuizamento de ações judiciais, atuam em sentido contrário, pois reputam mais vantajoso sujeitar-se a uma ação judicial do que manter ou instituir um sistema administrativo de tratamento adequado ao consumidor, pois, apenas uma parcela dos clientes insatisfeitos optará por provocar a tutela jurisdicional ou terá condições de fazê-lo.

Deste modo, deparamo-nos com a realidade brasileira que mantém uma cultura de litígio, vislumbrando que embora evidenciada a representativa parcela de responsabilidade da postura dos representantes dos setores bancário e de telefonia para o aumento de demandas judiciais, muitas vezes o próprio consumidor coopera para a litigação excessiva, pois sequer tenta resolver sua queixa com a própria instituição prestadora do serviço.

Nesse cenário, identificamos o acesso à justiça além da perspectiva do acesso ao judiciário, mas, sim, como forma por meio de instrumentos variados como os meios alternativos de solução de controvérsias e visualizamos os meios alternativos de solução de controvérsias, a conciliação, a mediação e a arbitragem como instrumentos 
adequados a conciliar, resolver os conflitos conferindo maior autonomia às partes e sem a provocação do Poder Judiciário, favorecendo a diminuição da taxa de congestionamento, inclusive nas hipóteses em que o Poder Público integre a relação jurídica processual.

Em seguida, estudamos os institutos da negociação, da conciliação, da mediação e da arbitragem, à luz da Resolução nº 125/2010 do CNJ, do Novo Código de Processo Civil, Lei n 13.105, de 16 de março de 2015, da Leis no 13.140, de 26 de junho de 2015, que dispõe sobre a mediação, e da Lei ${ }^{\circ}$ 13.129, que alterou a Lei 9.307/96, que dispõe sobre a arbitragem, estendendo a possibilidade de utilização da arbitragem para dirimir litígios relativos a direitos patrimoniais disponíveis do Poder Público, faculdade até então restrita aos particulares, às pessoas jurídicas de direito público.

Confirmamos a possibilidade de utilização da arbitragem nas relações de consumo, pois os direitos são disponíveis e art. 57, inciso VII, da Lei n ${ }^{o}$ 8.078/90, apenas considerou nulas de pleno direito as abusivas a inserção compulsória de cláusula compulsória de arbitragem nos contratos, de sorte que, havendo comum acordo, o instituto da arbitragem pode e deve ser aplicado nas relações de consumo.

Relativamente à redução da taxa de litigiosidade específica referente ao número de processos em que figuram como partes o Poder Público, os bancos e as empresas de telefonia, constatamos das análises realizadas que os meios alternativos de solução de controvérsias podem e devem ser utilizados como mecanismos auxiliares ao descongestionamento do Poder Judiciário proporcionando a solução dos conflitos na esfera extrajudicial ou mesmo, abreviando-se a solução da demanda por intermédio da conciliação ou da mediação judicial.

Quanto à atuação dos grandes litigantes, o acesso à justiça e à qualidade dos serviços judiciários, conforme pesquisa intitulada $\mathrm{O}$ uso da justiça e o litígio no Brasil, publicada em agosto/2015, pela Associação Brasileira de Magistrados, em menção ao estudo dos 100 maiores litigantes em 11 unidades da federação, estudada no terceiro item deste artigo, alinhando-nos ao pensamento de Maria Tereza Sadek, reputamos verificada a hipótese de que a atuação os dos grandes litigantes prejudica o acesso à justiça e a qualidade dos serviços judiciários, pois a máquina estatal acaba por 
dispensar boa parte seu tempo e recursos humanos na tramitação de processos que veiculam questões passíveis de composição ou solução extrajudicial.

\section{REFERÊNCIAS}

ALVARES, Laís Botelho Oliveira. Os meios alternativos de resolução de conflitos como coadjuvantes ao acesso à justiça. Revista das Faculdades Integradas Vianna Júnior - Vianna Sapiens. Juiz de Fora: 2012, V.3, N.2, jul-dez. Disponível em: http://www.viannajunior.edu.br/files/uploads/20131118_143058.pdf, acesso em 25.01.2016.

CAPPELlETTI, Mauro; GARTH, Bryant. Acesso à Justiça. Trad. Ellen Gracie Northfleet. Porto Alegre: Fabris, 1998.

CONCILIAÇÃO E MEDIAÇÃO. CNJ. Disponível em: http://www.cnj.jus.br/programas-e-acoes/conciliacao-mediacao, acesso 25.01.2016

COUTO, Monica Bonetti. MEYER-PFLUG, Samantha Ribeiro Meyer. Poder Judiciário, justiça e eficiência: caminhos e descaminhos rumo à justiça efetiva? In: SILVEIRA, Vladmir Oliveira da; MEZZAROBA, Orides et al (coord). Justiça e o paradigma da eficiência: celeridade processual e efetividade dos direitos. Curitiba: Clássica, 2013, pp. 131-145.

COUTO, Mônica Bonetti; TEIXEIRA, Laís Santana da Rocha Salvetti. O acesso à justiça e seu enquadramento como direito fundamental: contexto atual e evolução. In: COUTO, Mônica Bonetti; SILVA, Maria dos Remédios Fontes, TARTUCE, Fernanda.

Acesso à Justiça I. Florianópolis: FUNJAB, 2013.

;

O (direito fundamental ao) acesso à justiça no Brasil: por uma

correta compreensão. In: CASTRO, Matheus de; PEZZELA, Maria Cristina Cereser; RECKZIEGEL, Janaína. (org.). Direitos fundamentais civis: a ampliação dos direitos subjetivos no Brasil e na Alemanha (tomo II). 1 ed. Joaçaba: Unoesc, 2013.

ESTUDO COMPARADO SOBRE RECURSOS, LITIGIOSIDADE E PRODUTIVIDADE: a prestação jurisdicional no contexto internacional. Disponível em: http://www.cnj.jus.br/images/pesquisas-judiciarias/relat_estudo_comp_inter.pdf, acesso em 25.01.2016

GARCEZ, José Maria Rossani. Negociação, ADRs, Mediação, Conciliação $e$ Arbitragem. $2^{\mathrm{a}}$ ed., revista e ampliada. Rio de Janeiro: Lumen Iuris, 2004. 
LEAL, Rogério Gesta. Impactos econômicos e sociais das decisões judiciais: aspectos introdutórios. Brasília: ENFAM, 2010. Disponível em: http://www.enfam.jus.br/wpcontent/uploads/2014/04/Impactos-Economicos_site.pdf

LEITE, Carlos Henrique Bezerra. Direito e processo do trabalho: na perspectiva dos direitos humanos. Rio de Janeiro. Renovar. 2003. Apud CEZAR, Thyago. Acesso à justiça - um direito em crise. In: Âmbito Jurídico, Rio Grande, XVII, n. 121, fev 2014. Disponível em: $<$ http://ambitojuridico.com.br/site/?n_link=revista_artigos_leitura\&artigo_id=14476>. Acesso em 25.01.2016.

MACUSO, Rodolfo de Camargo. Acesso à Justiça (Condicionantes Legítimas e Ilegítimas). São Paulo: RT, 2011.

MARTINS, Pedro A. Batista. Acesso à justiça. In: MARTINS, Pedro A Batista; LEMES, Selma M. Ferreira; CARMONA, Carlos Alberto (Coord). Aspectos fundamentais da lei de arbitragem. Rio de Janeiro: Forense, 1999.

O USO DA JUSTIÇA E O LITÍGIO NO BRASIL. Relatório encomendado pela Associação dos Magistrados Brasileiros (AMB). Coordenação Maria Tereza Sadek. Disponível em: https://www.placardajustica.com.br/assets/files/placardajustica_o_uso_da_justica_e_o_1 itigio_no_brasil.pdf , acesso em 12.01.2016

Relatório DEMANDAS REPETITIVAS E A MOROSIDADE NA JUSTIÇA CÍVEL BRASILEIRA. Disponível em http://www.cnj.jus.br/images/pesquisasjudiciarias/Publicacoes/pesq_sintese_morosidade_dpj.pdf , acesso em 12.01.2016.

Relatório "100 MAIORES LITIGANTES 2011”, Disponível em: http://www.cnj.jus.br/images/pesquisasjudiciarias/Publicacoes/100_maiores_litigantes.pdf,_Acesso em 20.01.2016

RESOLUÇÃO 125/2010 CNJ. Diponível em http://www.cnj.jus.br/busca-atos$\underline{\text { adm?documento }=2579}$, acesso em 25.01.2016.

SILVA, Adriana S. Acesso à Justiça e à arbitragem: um caminho para a crise do Judiciário. Barueri: Manole, 199.

TORRES, Ana Flavia Melo. Acesso à Justiça. In: Âmbito Jurídico, Rio Grande, III, n. 10, ago 2002. Disponível em: $\quad \underline{\text { http://www.ambito- }}$ juridico.com.br/site/index.php?n_link=revista_artigos_leitura\&artigo_id=4592> $>$. Acesso em jan 2016.

WATANABE, Kazuo. Política Pública do Poder Judiciário Nacional para tratamento adequado dos conflitos de interesses. Parecer ao TJ-SP. Disponível em 
http://www.tjsp.jus.br/download/conciliacao/nucleo/parecerdeskazuowatanabe.pdf, acesso em 25.01.2016 